\title{
EDUCATIONAL MANAGEMENT AND PERFORMANCE OF SCHOOL ORGANIZATIONS
}

\author{
Nicuşor DIACONU ${ }^{a}$, Cornelia PETRE $(\mathrm{STAN})^{b}$, Loredana Elena COMĂNESCU \\ a,b,c Valahia University from Târgoviște, Romania
}

\begin{abstract}
The notion of quality at the level of school organizations, as well as the need to modernize and align with European trends in quality in education is still identified as organizational conservatism, coupled with the lack of information on current trends in school development, based on the notion of quality. The ways of evaluating the efficiency in the education system are presented from the perspective of evaluating the efficiency of the teaching activity. School effectiveness is a difficult concept to measure, because it is related to different criteria, defined depending on the specifics of each school, the results of students and the added value of the school. This paper aims to highlight the role and importance of quality in Romanian pre-university education.
\end{abstract}

KEYWORDS: effectiveness, quality, quality assurance, results, system, teaching activity

DOI: 10.24818/IMC/2021/02.21

\section{INTRODUCTION}

European initiatives on the quality of education, even if they are recent (about a decade), already highlight a number of common directions for development, established by consensus at the level of European and international institutions. These directions will have to be taken into account when building the national management and quality assurance systems, including the Romanian ones. This alignment is necessary, on the one hand, to ensure a real and functional integration, from an educational point of view, of Romania in the European Union and, on the other hand, for the Romanian initiatives in this field to be consonant, in terms of theoretically and methodologically with what is happening now in the world. A lag in the design of quality management and assurance systems, subsumed values and related methodologies would make it extremely difficult not only to integrate, but even to understand each other. The most important European initiatives on the quality of education have taken place in higher education and vocational education and training. The reasons are obvious: on the one hand, the need to increase the competitiveness of education leading to qualifications on the international market and, on the other hand, the need to make education and training systems compatible from the perspective of free movement of labor and, implicitly, of qualifications.

In the Romanian system, Quality Management has been replaced by quality management in education. Very important is the role of human resources and the role of conditions created to achieve the objectives proposed to ensure the quality of the educational act to achieve performance. Also important is the behavioral manner in which pre-university education units will operate.

Quality in education or quality education is the fundamental idea behind the proposed scientific approach, this means to identify the fundamental components to work with: theoretical dimension 
(by defining concepts and associated meanings), axiological dimension (by embedded values) and systemic dimension (interactions between components).

The social status of the school, the qualitative expectations of the beneficiaries of education, the contradictory changes in the pre-university education system and the social dimension of the school organization are factors that imperatively emphasize the need for quality management in education. The relationship between the development of the concept of quality and the context in which it evolved is a complex issue, which is interesting both as a starting point (analysis of existing approaches) and as a possibility to return (after a series of research) to improve existing concepts. Herodot (484-425 b. Chr. - Greek historian, also known as the "father of history") is perhaps the one who offers a first definition of quality, that of "a job well done" and which, at the time, was confirmed by the application of a stamp (stamp or mark) of the manufacturer, workshop or city of origin on the created objects (vessels, weapons, various tools, ceramic objects, etc.).

A precedent for what is now called the "era of quality control" can be considered the military system established within the communities, a system that, as a general rule, has focused on standardization, control and compliance. The most eloquent and perfect example in this respect is the Romanian military system, perhaps due to the fact that the Romanian state was an eminently military state (Military service was compulsory for all citizens aged 17 to 60). In fact, the romanians are the first to correlate the quality and mass production.

\section{QUALITY IN ROMANIAN PRE-UNIVERSITY EDUCATION}

With Romania's integration into the European Union, the issue of the efficiency of our education system also arose. This involves an analysis that looks at several aspects: The standard of living of the population: the level of well-being and technology has increased in recent years in our country, but the number of people living in poverty is still quite high. The chances of recovery are to create an effective education system (Holmberg, 2017). In fact, the romanians are the first to correlate the quality and mass production.

Globalization: the activities of society, including education, are closely dependent on the world; globalization implies a high level of culture and civilization of different peoples, which is impossible to achieve without an efficient and modern education system (Agasisti, 2011).

Unemployment rate: the professional training of an individual is related to unemployment; a priori we can say that unemployment rates decrease as the professional, educational, training of the individual increases; an inefficient education system leads to a low level of education, which explains the level of unemployment in a country (Dandeș, 2017). The field of education has undergone, in the last 20 years, many structural and content changes, accompanied by updates of the concepts with which it operates. Thus, the notion of administration - which has become much less comprehensive - is replaced by educational management, then, more recently, educational leadership joins. Practice has shown that real leadership and quality management are decisive factors in differentiating educational organizations that evolve under similar conditions. The role of leaders is to determine the extent to which the organizations they lead are prepared to meet the challenges and - at the same time - to develop the skills needed to manage them. In education, leadership must take on irreversible transformations, based on the personal and educational values of leaders, translated into institutional objectives and doubled by visionary strategies; what must be 
remembered is that - unlike other areas - education is a strategic area, with centralized policies and strategies. Here, the leader's ability to harmonize his vision with the national strategy and to deliver to the organization the road to a quality education, beyond the limitations of the system, intervenes. Performance is a managerial concept that can be quantified through the efficiency and effectiveness of an entity. Defining performance can be difficult due to the versatile interpretations existing in the literature. The term performance can be defined at various levels: personal performance, individual performance, performance of the department or organization. Effectiveness is the extent to which an action achieves a well-defined goal. Efficiency is the ratio between the effects of achieving the proposed goal and efforts. With Romania's integration into the European Union, the issue of the efficiency of our education system also arose.

School effectiveness is a difficult concept to measure, because it is related to different criteria, defined according to the specifics of each school, the results of students and the added value of the school. For this, the firm parameters, current objectives, performance standards that must be reached in order for the activity to be considered fulfilled are established (Iosifescu, 2010).

This article wants to highlight the role and importance of quality in Romanian pre-university education. The first issue that stands out is the misperception of the notion of quality in school organizations, as well as the need to modernize and align with European trends in quality in education. Responsible for this issue is identified as organizational conservatism, coupled with the lack of information on current trends in the development of schools, based on the notion of quality. The scientific problem is the declining performance of the pre-university education system, performance reflected by the results of the national exams the results obtained by our students in PISA tests, the poor results obtained at the National Titularization Contest in Pre-university Education, the insertion of socio-professional on the labor market.

The Ministry of Education, regardless of its name in recent years, has tried to identify ways to increase the quality of national education, as follows:

- In 2000, the Ministry of Education made available to schools units for the creation of educational sites;

- In 2003 the principals of school units are asked to draw up Management Plans and Operational Plans;

- In 2005, quality standards established by ARACIP are piloted, aiming at increasing the quality of the educational act;

- In 2006 the school units elaborate the first operational procedures and Annual Performance Evaluation Sheets for teachers;

- In 2007 the principals of the school units draw up the first PDI and the first RAEI selfassessment reports of the quality of education in the unit that ARACIP transmits, also fields of activity are made available to the school units on the MOODLE Platform;

- In 2011 the new Education Law is approved, teachers must participate in training courses accredited by CCD for the accumulation of 90 professional credits;

- In 2012, funding is allocated per student, the school budgets being made up of these revenues, which requires a competence between units in attracting students;

- In 2015 ARACIP launches through the strategic project POSDRU 2007-2013- ID 55668 "Support for school units in the implementation of the manual for internal evaluation of 
the quality of education", the platforms: https://calitate.aracip.eu/ and https: // aracip. eu / used for CEAC in completing the Quality Circle and elaborating the RAEI;

- In 2020, the Romanian Government adopts DECISION no. 993 of November 18, 2020 on the approval of the Institutional Evaluation Methodology in order to authorize, accredit and periodically evaluate the organizations providing education and DECISION no. 994 of November 18, 2020 on the approval of the standards for the authorization of provisional operation and of the standards of accreditation and periodic external evaluation in pre-university education.

Effectiveness is the extent to which an action achieves a well-defined goal. Efficiency is the ratio between the effects of achieving the proposed goal and efforts. With Romania's integration into the European Union, the issue of the efficiency of our education system was raised through an analysis that would follow several aspects:

$\checkmark$ The living standard of the population: the level of well-being and technology has increased in recent years in our country, but the number of people living in poverty is still quite high. The chances of recovery are to create an effective education system (Holmberg, 2017);

$\checkmark$ Globalization: the activities of society, including education, are closely dependent on the world; globalization implies a high level of culture and civilization of different peoples, which is impossible to achieve without an efficient and modern education system (Agasisti, 2011);

$\checkmark$ Unemployment rate: the professional training of an individual is related to unemployment; a priori we can say that unemployment rates decrease as the professional, educational, training of the individual increases; an inefficient education system leads to a low level of education, which explains the level of unemployment in a country (Dandes, 2017).

The ways to evaluate the efficiency in the education system are presented from several perspectives in the table below:

Table 1. Perspectives for evaluating the efficiency of teaching activity

\begin{tabular}{|l|l|}
\hline Perspective & The ontological dimensions of perspectives \\
\hline $\begin{array}{l}\text { From the perspective of the designed } \\
\text { objectives }\end{array}$ & $\begin{array}{l}\text { Efficiency is measured in the number and } \\
\text { quality of objectives achieved }\end{array}$ \\
\hline $\begin{array}{l}\text { From the perspective of the functioning of the } \\
\text { school institution as a system }\end{array}$ & $\begin{array}{l}\text { The way in which the inputs: material, human, } \\
\text { pedagogical, contextual resources, participate } \\
\text { in the teaching process to get a number of well- } \\
\text { trained graduates; }\end{array}$ \\
\hline From a relational perspective & $\begin{array}{l}\text { From the point of view of interpersonal } \\
\text { relations: students-teachers, teachers- } \\
\text { management (CA, CP, Director), students- } \\
\text { students, reflected in the increase of the quality } \\
\text { of the educational act itself. }\end{array}$ \\
\hline
\end{tabular}




\begin{tabular}{|l|l|}
\hline Perspective & The ontological dimensions of perspectives \\
\hline From an institutional perspective & $\begin{array}{l}\text { The evaluation is done according to the } \\
\text { organizational chart. The functionality and } \\
\text { contribution of each department are measured, } \\
\text { to the good functioning of the school unit; }\end{array}$ \\
\hline From statistical perspective & $\begin{array}{l}\text { The evaluation is made on the basis of the } \\
\text { percentage of passability in the national } \\
\text { evaluations and on the basis of the insertion } \\
\text { rate of the graduates on the labor market. }\end{array}$ \\
\hline
\end{tabular}

Source: the author

School effectiveness is a difficult concept to measure, because it is related to different criteria, defined according to the specifics of each school, student results and information added by the school. For this, the firm parameters are established, current objectives, performance standards that must be reached in order for the activity to be considered fulfilled (Iosifescu, 2010).

In general dictionaries quality is defined as a level or degree of excellence, value or merit, associated with a particular object, product, service or person. Starting from this very general definition, let's see where the attempts to materialize at the level of education lead us. First of all, a "good" quality thing has no defects.

But what does "flawless" mean? First of all, the product or service must correspond to the purpose for which it was created: a knife must, first of all, cut, a school must, first of all, do education. But both knives and schools are differentiated, depending on the destination of the product, respectively the service: the knives can be large or small, with no tip, with wooden or plastic handle, with black or red handle, etc; schools provide certain knowledge, skills and competencies to students of a certain cycle/form of education. Therefore, in order to define "defect" we must describe, very precisely, what the respective product or service must be what are its essential characteristics which define it by another product or service.

These descriptions of the products or services are called "specifications", and the expected level of fulfillment of these specifications is called "standards". For products, for example, these specifications refer to the purpose of the product's existence, size, shape, color, destination, etc., and standards refer to strength, durability, operational safety, etc.

The Agency for Quality Assurance in Pre-University Education is the only institution authorized in Romania to evaluate educational units. It has established provisional authorization standards for the establishment of an educational unit and standards for accreditation and periodic evaluation.

The Romanian standards are:

1. national standards;

2. general standards;

3. identical standards for the public and private subsystem;

4. unique standards for internal evaluation (self-evaluation) and external evaluation;

5. common standards for all educational authorities with the role of evaluation, monitoring, control. Since 2015, ARACIP has launched through a strategic project POSDRU 2007-2013 "Support for school units in implementing the manual for internal evaluation of the quality of education" - ID 55668, piloted on 200 state and private pre-university education units: kindergartens, primary 
schools, middle schools, high schools and post-secondary schools, two platforms for the Quality of education: https://calitate.aracip.eu/ and https://aracip.eu/ .

All pre-university education units in Romania, state and private, have free access to https://calitate.aracip.eu/ where all the identification data of the school unit are registered and are generated annually in October until the 15th Report Annual Internal Quality Assessment of the unit after it was generated at the beginning of the school year using the Centralizer, which is actually Deming's Circle: Quality, Productivity and Competitive Position.

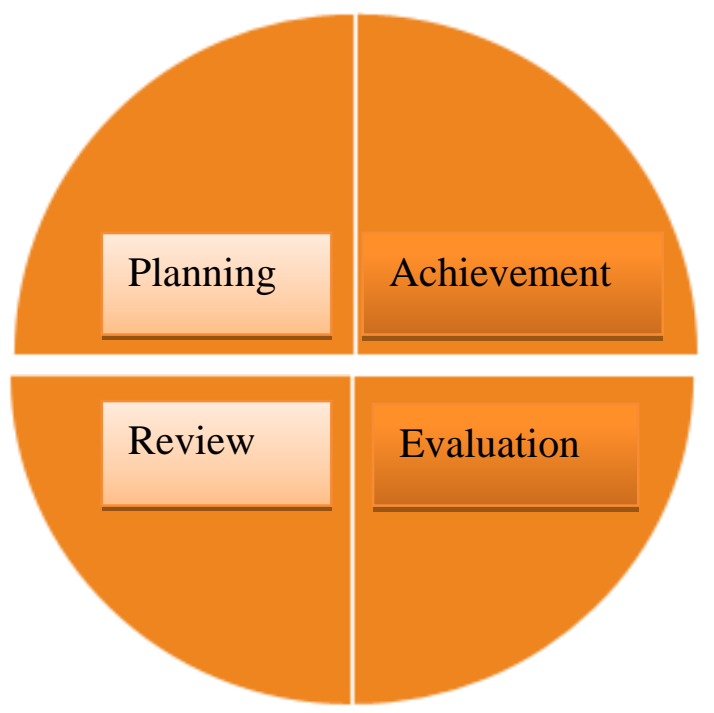

Figure 1. The centralizer. Performance management cycle.

Source: https://calitate.aracip.eu/

The processes that take place in the performance cycle, one school year September 1-August 31 the following year are:

- PLANNING: it is done through the quality improvement plan made by CEAC. It has as its starting point the Internal Quality Assurance Strategy and will take into account the strategic targets contained in that document. The internal quality assessment strategy will be based, in turn (and will have the same time horizon) on the institutional development project of each school unit. If the strategic targets in the PDI are formulated in terms of quality increase, naturally, they will also become targets of the internal quality assurance strategy. The latter can be supplemented with operational plans - annual, semiannual monthly, depending on the option of the school.

- ACHIEVEMENT: in this stage the activities of quality improvement and internal evaluation are recorded, carried out according to the planning from the previous RAEI. Unplanned activities can also be registered, established during the current quality year.

- EVALUATION: the level of achievement of the indicators for each creditable level is completed. For a correct completion, the descriptors corresponding to each indicator are taken into account. This stage must ensure the processing and interpretation of the data collected following the quality improvement activities and the application of the investigation / diagnosis tools. Internal evaluation must provide solid, reliable data on the extent of the changes made: whether the changes are only superficial, made out of 
conformity or imitation, or whether, on the contrary, the changes are profound, truly and sustainably affecting the whole school activity.

- REVIEW: by judging the results of the evaluation, the reflection on them and the decision on the development priorities, negotiated with the main stakeholders (especially with the beneficiaries of education). This decision will substantiate the next quality improvement plan and re-entry into the "quality circle".

\section{The internal evaluation must follow the "quality circle". It must:}

1. Planned from October (by consulting the school and community database, by identifying problems, by defining the methodology and tools of internal evaluation, by establishing the objectives, resources, deadlines, responsibilities and indicators pursued);

2. Achieved (by applying internal evaluation tools and by collecting, analyzing and synthesizing the data obtained);

3. Evaluated (by analyzing and interpreting the results of the internal evaluation and by carrying out the internal evaluation report - RAEI);

4. Revised (by judging the results and by substantiating, based on the evidence obtained, the decision to improve - therefore, by using the results of the internal evaluation to improve quality).

\section{CONCLUSIONS}

School organizations provide services whose quality influences the development of the communities of which they are part. The particularities of the services require a specific approach to their quality, so the quality indicators must be adapted to these particularities.

The multidimensional character of the pre-university education system as well as the diversity of methods for achieving a quality education depends on:

- The management of the school unit that must listen to the opinions of the teaching and auxiliary teaching staff, but also of the non-teaching staff;

- Teachers who are involved and consulted in planning, conducting and attracting additional resources to finance extracurricular activities;

- Participation in the decision-making process in the school unit, both teachers and parents, for their active involvement in the quality of education provided to students;

- Participation of teachers in scientific research activities, methodical activities, or training courses to achieve the quality of education provided by the school.

All this leads to an urgent need to ensure the quality of education. The article presents a balanced approach between knowledge in the field of quality assurance of education and practical implications.

Over time, the quality of education has been defined from several perspectives covered in the first chapters. Postmodern society requires the involvement of school organizations in designing and achieving positive formative goals, educational leadership manifesting itself in flexible environments, open to change.

Change in school organizations is a complex process that involves: members of the organization, beneficiaries of education and the community. Routine participation of members highlights the 
dynamic nature of the organization and their involvement in the process of change. The quality of education from the perspective of change in the field of pre-university education has a major role: it determines the progress of contemporary society and favors adaptability in a competitive context. The quality of education, from the perspective of change, materializes in the quality of educational services, in creating trust and adopting those measures aimed at achieving the optimal objectives. The director, captivated and connected to everyday realities is completely dedicated to certain tasks: the effectiveness and implementation of change. By proposing actions that shape attitudes and beliefs, he is at the heart of the organizational context. The principal must adopt a style that capitalizes on: the competencies of the members of the school organization, the development of collective competencies and the proactive involvement in the process of changing the school as a social organization. The director has the ability to reduce resistance to change. Having empathic ability, showing conviction, he stimulates interpersonal interactions, motivates and captures the interest of supporters. It does not resort to simplistic procedures for solving fundamental problems in school organizations and does not use unscientific strategies. His professional skills determine the emotional and effective participation of members of the organization in implementing change. School organizations need leaders who define a vision, that is, a proactive and positive image of the future.

In school organizations, the leader is able to set educational goals, bring together, mobilize and influence the members of the organization so that they orient their behaviors towards the defined vision. The component elements of the vision are reunited in the description of a new world, with people, images and sensations that address the imagination of each one, using an evocative, open, coherent and complementary vocabulary. The vision required intuition, desire and emotion being rooted in the values, skills and aspirations of the members of the organization. Quality must influence the members of the group in the desired direction, communicating effectively with the management and obtaining the expected behaviors. All members of the organization will act around a common vision and give authority to the people involved, so that they can act consistently and with well-defined guidelines.

Building a vision and a future shared by several members of the organization ensures the effective development of actions designed to bring about change. The management of the unit must anticipate the possible behaviours of the group or of the people put in front of the change, the will of the members of the organization to cooperate being variable: some people are for change, others are waiting, others are hostile to change. Aware of the representation he has towards his own position and towards the members of the organization, the director will build trusting relationships, of the winner-winner type. The unit will make a major qualitative leap if it succeeds in integrating new methods of achieving quality. In their absence, members of the organization may enter the next spiral of demotivation: fatigue (loss of energy, isolation, slowing down), alibis (loss of meaning, open criticism, irresponsibility), offsaid (loss of landmarks, mistrust) and sabotage (conscious attempts or unconscious). Leadership must have the ability to manage one's own emotions and the ability to manage the emotions of others. 


\section{REFERENCES}

Agasisti, T. (2011). How competition affects schols'performances: Does specification matter? Economics Letters 110(3), 259-261

Dandeș, A. A. (2017). Emplayment Unemplayment Benefits And The European Social Policy. Ecoforum 6(1), 141

Holmberg, J. (2017). The Relative Efficiency of Swedish Secondary Schools: An estimation using Stochastic Frontier Analysis, UMEA Universtet, p. 2-3. Retrieved from https://www.divaportal.org/smash/get/diva2:1120758/FULLTEXT01.pdf

Iosifescu, C. S. (2010). Quality in the Romanian school through Standards and Reference Standards. General Guide, p. 8

"Internal evaluation manual" elaborated within the Strategic Project "Support for school units in the implementation of the internal evaluation evaluation of the quality of education" - ID 55668, project co-financed from the European Social Fund through the Sectoral Operational Program Human Resources Development 2007-2013, Retrieved from https://calitate.aracip.eu/, https://aracip.eu/

Răboacă, G. \& Ciucur, D. (2013). Methodology of economic scientific research, 3rd edition, Bucharest:Ed. ASE

The Government of Romania (2020a). Decision no. 993 of November 18, 2020 on the approval of the Institutional Evaluation Methodology for the Authorization, Accreditation and Periodic Evaluation of Educational Organizations, published in the Official Gazette no. 1205 of December 10, 2020, Romania. Retrieved from http://legislatie.just.ro/Public/DetaliiDocument/234510

The Government of Romania (2020b). Decision no. 994 of November 18, 2020 on the approval of the standards for the authorization of provisional operation and of the standards of accreditation and periodic external evaluation in pre-university education, published in the Official Gazette no. 1225 of December 14, 2020, Romania. Retrieved from http://legislatie.just.ro/Public/DetaliiDocumentAfis/235162 